\title{
LITERATURA E CONSTRUÇÃO DE UMA BRASILIDADE PELA CULINÁRIA (1840-1960)
}

\section{LITERATURA Y CONSTRUCCIÓN DE UNA BRASILIDAD POR LA CULINARIA (1840-1960)}

FELICIANO, Paula de Oliveira ${ }^{1}$

RESUMO: Em contraponto às cozinhas europeias e suas estruturas de compreensão eruditas, a construção identitária da cozinha brasileira é objeto recente de estudos acadêmicos mais aprofundados. A literatura e as artes do final do século XIX e meados dos XX contribuíram também para moldar, cristalizar e comunicar a formação de uma mitológica história cultural brasileira. Desta forma, tais cristalizações se articularam e se materializaram em diversos simbolismos e expressões que compõem a cultura material e imaterial, incluindo a cozinha. Assim, o objetivo deste artigo é mostrar informações sobre a literatura culinária dedicada a apresentar a cozinha brasileira no período de 1840 e 1960. Em seguida, visa à descrição de evidências do interesse de Mário de Andrade pela construção de uma brasilidade pela culinária. A metodologia incluiu levantamento bibliográfico e pesquisa de campo no acervo de Mário de Andrade existente no Instituto de Estudos Brasileiros da Universidade de São Paulo (IEB-USP).

PALAVRAS-CHAVE: Cozinha Brasileira, Literatura, Mário de Andrade.

RESUMEN: En contraposición a las cocinas europeas y sus estructuras de comprensión eruditas, la construcción identitaria de la cocina brasileña es objeto reciente de estudios académicos más profundos. La literatura y las artes de finales del siglo XIX y mediados de los XX contribuyeron también a moldear, cristalizar y comunicar la formación de una mitológica historia cultural brasileña. De esta forma, tales cristalizaciones se articulan y se materializaron en diversos simbolismos y expresiones que componen la cultura material e inmaterial, incluyendo la cocina. Así, el objetivo de este artículo es mostrar informaciones sobre la

\footnotetext{
${ }^{1}$ Docente no Centro Universitário Senac Campos do Jordão/SP. Mestranda no programa de pós-graduação em Culturas e Identidades Brasileiras, do Instituto de Estudos Brasileiros da USP (IEB-USP), especialista em Docência para o Ensino Superior, pelo Centro Universitário Senac São Paulo (2012) e em Administração Hoteleira pelo Centro Universitário Senac São Paulo (2009). E-mail: pafeliciano@gmail.com
}

Jangada | nr. 11, jan/jun, 2018 | ISSN 2317-4722 


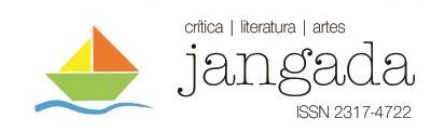

literatura culinaria dedicada a presentar la cocina brasileña en el período de 1840 y 1960 . A continuación, apunta a la descripción de evidencias del interés de Mário de Andrade por la construcción de una brasilidad por la culinaria. la metodología incluyó levantamiento bibliográfico e investigación de campo en el acervo de Mário de Andrade existente en el Instituto de Estudios Brasileños de la Universidad de São Paulo (IEB-USP)

PALABRAS CLAVES: Cocina Brasileña, Literatura, Mário de Andrade.

\section{INTRODUÇÃO}

A compilação de receitas culinárias é uma atividade que se têm notícia desde a Antiguidade. O tratado de Apício denominado De re coquinaria reunia, por exemplo, informações sobre a cozinha romana. Nesta época (e nos séculos seguintes) a troca de conhecimentos culinários estava limitada aos círculos das elites e também se transmitiam informações sobre os hábitos de alimentação e modos à mesa.

Com a invenção da tipografia no século XV, "surgem os primeiros livros impressos de culinária, que facilitam e aceleram a difusão mais ampla de receitas". Estas, eram escritas por cozinheiros reconhecidos a serviço da alta nobreza. (TREFZER, 2009, p. 11)

Da Idade Média até o século XVIII são considerados "preciosidades, símbolos de status [e] cuidadosamente conservados". Neste último século, passam a existir também aqueles escritos como fonte de conhecimentos sobre assuntos domésticos, com a função de transmitir informações básicas para a administração do lar. (TREFZER, 2009, p. 13)

É interessante observar como os conhecimentos culinários documentados, seja por meio de tratados e manuscritos, seja por meio de livros de receitas, possuem diferentes funções no curso da História. Essa documentação nos permite, embora de forma não isolada, obter um grande número de informações reveladoras sobre transformações socioculturais, políticas e econômicas.

A partir deste contexto, este artigo buscar mostrar informações sobre a literatura culinária dedicada a apresentar a cozinha brasileira no período de 1840 e 1960. Em seguida, visa à descrição de evidências do interesse de Mário de Andrade pela construção de uma brasilidade pela culinária. 


\section{N jangada}

\subsection{METODOLOGIA}

Foram utilizadas referências bibliográficas presentes em livros e nas bases de dados Scielo, Capes e sites da internet. As conexões teóricas apresentadas visam explorar o tema da literatura culinária como meio para a construção de uma brasilidade no período de 1840 e 1960; período que inclui a primeira e a última publicação de referência para o estudo da cozinha brasileira. $\mathrm{O}$ interesse de Mário de Andrade com relação a essa temática fez com que ele fosse objeto de atenção especial na construção desse artigo, razão pela qual seus estudos (disponíveis no acervo do Instituto de Estudos Brasileiros da Universidade de São Paulo - IEB-USP) foram de grande valia ao longo da redação deste trabalho.

\section{DOCUMENTAÇÕES SOBRE IDENTIDADE NACIONAL PELA CULINÁRIA ENTRE OS SÉCULOS XIX E XX}

Em contraponto às cozinhas europeias e suas estruturas de compreensão eruditas, a construção identitária da cozinha brasileira é objeto recente de estudos acadêmicos mais aprofundados. Somado a isso, pode-se citar a inexistência de um conceito formal que unifique a cozinha brasileira; não raro exemplificamos nossa cozinha por meio de receitas, assim, quando identificamos a cozinha baiana, por exemplo, referimo-nos ao vatapá e ao acarajé, a cozinha mineira relacionamos ao tutu. (DÓRIA, 2014).

Bibliografias que problematizam a formação da culinária brasileira no final XIX não são identificadas e o mais comum são publicações de livros de receitas nos moldes do que se tinha na Europa. O Brasil, sob influência do período pós-Napoleônico, passou a comer à francesa, já que no século XIX Paris era a capital do mundo burguês. Estes hábitos se consolidaram no Rio de Janeiro e se difundiram pelas casas-grandes dos engenhos. Neste período, jornais cariocas publicavam anúncios à procura de cozinheiros franceses ou aptos a realizar cardápios domésticos baseados nessa tradição, como garantia de excelência (DÓRIA, 2014).

A criação do Instituto Histórico Geográfico Brasileiro (IHBG) no país, em 1839, trouxe consigo o lançamento de "um concurso para a escrita da história nacional". O vencedor foi Karl Von Martius, que apresentou "a ideia de que a bandeira central do país seria a miscigenação" entre brancos, negros e índios. (LEME; BASSO, 2014, p. 20) 
Segundo levantamento do historiador Tim Wätzold, em seu livro A Proclamação da Cozinha Brasileira Como Parte do Processo de Formação da Identidade Nacional No Império Brasileiro (1822-1889), data de 1840 a primeira edição do livro O Cozinheiro Imperial, sob o pseudônimo R. C. M. Nele constatou-se "o fato de que a maioria das receitas foi em parte copiada literalmente dos livros de culinária portugueses”. Em seu prefácio, atribui-se à arte culinária utilidade indispensável ao homem civilizado e este "conhecimento [estaria] relacionado com àqueles que vivem nas nações europeias, progressistas em civilização e indústria”. (WÄTZOLD, 2012, p. 155-156). Em sua quarta edição, em 1859, identifica-se, segundo ele, "a primeira vez que se intitulava [aqui] uma receita de 'à brasileira'. Além disso, a receita não teria sido copiada de um livro de receitas português”. (W ÄTZOLD, 2012, p. 158).

Em 1851 os mesmos editores do Cozinheiro Imperial lançaram o livro Doceira Brasileira. Este é tido como baseado em livros portugueses, porém, acrescido de ingredientes nacionais. O destaque vai para receitas de pastéis republicanos, num indício de como a alimentação era influenciada pelos acontecimentos políticos e, de certo modo, seu instrumento.

Em 1859, lança-se no Brasil o Guia Do Criado De Servir ou Observações Úteis A Criados E A Donas De Casa, por Constança Olívia de Lima. O livro, não era nada do que cópia completa do livro Guia do Criado de Servir, Livro Útil a Criados e a Donos de Casa, publicado em Lisboa, em 1851.

Em 1875 é lançado no Rio de Janeiro A Doceira Doméstica; impresso em Paris, foi redigido por Dona Anna Correa e publicado pelo editor J. G. de Azevedo. Destaca-se nesta publicação a primeira vez em que a receita do doce manjar branco não incluía como ingrediente peito de frango (comum desde o século XVI), mas farinha de arroz.

Em 1875 (ou 1870, sua data de publicação é incerta; teve reedições em 1885, 1889, 1892, 1910 e 2008), surgiu o primeiro livro que se pretendia pertencente à culinária nacional, chamado Cozinheiro Nacional, editado em Paris e de autor anônimo. Este foi escrito na tentativa de edificar "uma culinária brasileira fundamentada nos sabores da terra". ${ }^{22}$ Além disso, uma análise minuciosa das preparações e métodos de cocção permite visualizar a

\footnotetext{
2 Estes "sabores da terra" seriam abordados no Cozinheiro Nacional numa sugestão, até então inédita nos livros de receitas do Brasil, de substituições de ingredientes estrangeiros com relação ao que se dispunha aqui. $O$ historiador Wätzold (2012, p. 183) apresenta um trecho do prefácio deste livro para ilustrar como o livro aborda "o desenvolvimento e a percepção do Brasil no âmbito mundial: (...) Porque é tempo que o Brasil se dispa de suas vestes infantis, e que, abandonando os costumes de imitar as mais nações, se apresente aos olhos do mundo, ocupando o lugar distinto que a natureza lhe marcou".
} 


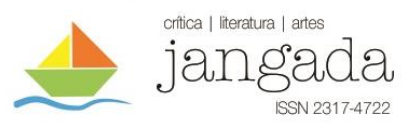

sugestão de substituição por ingredientes nacionais numa sistemática e gramática culinárias, em essência, da escola de cozinha clássica francesa. Verifica-se que esta publicação não reflete o que se come no país, mas "o que a elite quer comer como signo de nacionalidade" (DÓRIA, 2008, pp. 25-26, apud Cozinheiro Nacional, 2008). Destaca-se, no capítulo das sobremesas, o fato de que à maioria das receitas adiciona-se o termo "à brazileira".

Segundo o levantamento de Wätzold, embora sem identificar em qual edição ou reedição tal informação teria aparecido pela primeira vez, a receita do que reconhecemos hoje como feijoada teria sido descrita neste livro como "feijão preto à moda brasileira". De acordo com Elias (2004), esta receita já teria aparecido no livro Cozinheiro Imperial, em 1840.

A importância da feijoada neste contexto é que o prato é um exemplo de receita considerada "tipicamente brasileira", "convencionada"3 há tempos como aquela que representaria a fusão do Brasil: o feijão como elemento indígena e a preparação em si como fruto de produção culinária de herança das senzalas, conquistando todas as classes sociais. Para Elias (2009, p. 38), “o que se sabe de concreto é que as referências mais antigas à feijoada não têm nenhuma relação com escravos ou senzalas, mas sim a restaurantes freqüentados pela elite escravocrata urbana". Tal fato poderia ser identificado em anúncio do menu do Hotel Théâtre, no Diário de Pernambuco de 7 de agosto de 1833, e em anúncio do Jornal do Commercio de 5 de janeiro de 1849, no Rio de Janeiro.

A alimentação, vista sua necessidade fisiológica, por isso essencial, está aportada na cultura cotidiana do ser humano tanto em relação aos meios, às formas e circunstâncias de preparo e consumo, influenciando os comportamentos e a cultura material. A feijoada é somente um exemplo a ser considerado de como a alimentação pode ser utilizada para refletir a diferenciação dos grupos e estruturas sociais e, nesse sentido, auxiliar na construção de uma identidade nacional (WÄTZOLD, 2012). Poulain (2013, p. 34) reforça ainda que os

produtos alimentares (quer seja ou não elaborados), objetos e habilidades

\footnotetext{
${ }^{3}$ Segundo o antropólogo Claude Papavero, até o século XVIII o feijão não era um ingrediente apreciado pelos colonos lusos devido à sua dificuldade de digestão. Posteriormente teriam sido incluídos como elementos básicos da dieta brasileira especialmente porque eram considerados substanciosos e válidos para a nutrição apenas dos trabalhadores braçais (escravos). Destaca-se ainda a pesquisa de Mônica Chaves Abdala, que considera a mistura de feijões e carnes (algo mais próximo à feijoada) como elemento da dieta dos bandeirantes e, depois dos tropeiros, pela obtenção rápida da safra da leguminosa, sua armazenagem, conservação e transporte. As carnes seriam elemento de aporte também de sabor e calorias para os longos trajetos de viagem e em nada teriam de correlação à dieta de pobres e escravos. PAPAVERO, Claude. Dos feijões à feijoada: a transformação de um gênero comestível pouco apreciado em mantimento básico brasileiro (2008, p. 15).
} 


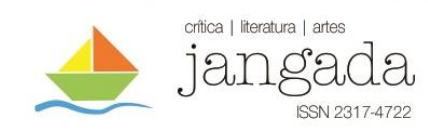

utilizados em sua produção, em sua transformação, em sua conservação e em seu consumo, assim como os códigos sociais, 'os modos de cozinhar' e os 'modos comer e beber' são objetos culturais" [que possuem] "uma parte da história e da identidade de um grupo social.

WÄTZOLD (2012, p. 211) reitera que os processos de transformação política e social no Brasil do século XIX foram

\begin{abstract}
acompanhados indiretamente nos livros de culinária como, por exemplo, ao lançar pratos brasileiros nas novas edições do Cozinheiro Imperial ou também com a publicação do livro Doceira Brasileira. Como conclusão deste processo de transição da formação da identidade e no discurso nacionalista, a Editora Garnier publicou o livro de culinária Cozinheiro Nacional, que, da mesma forma, instrumentalizava e trabalhava este processo e discurso no sentido culinário, na forma da proclamação de uma cozinha brasileira.
\end{abstract}

Ainda sob o reflexo da constituição de uma identidade brasileira por meio de uma cozinha nacional, segundo Wätzold (2012, p. 211) há que se ressaltar o papel da alimentação na "consolidação duradoura de outras identidades; (...) a alimentação regional representa um modelo de identificação extremamente importante, pelo qual a região e seus habitantes se representam para fora". As cozinhas regionais, assim como a própria designação de seus habitantes (paulistas, mineiros, nordestinos, gaúchos, etc.) foram estabelecidas, e se cristalizaram, de acordo com as divisões geopolíticas. Contradição esta, haja vista não haverem considerado o material natural - a biodiversidade - que é próprio e inerente às escolhas e ao fazer culinário. São muitas as discrepâncias entre o discurso divulgado pelas elites intelectuais e a realidade alimentar nacional neste período final do século XIX.

Após a última edição do livro Cozinheiro Nacional no século XX (1910), autores como Monteiro Lobato e Gilberto Freyre incluem vários elementos da cultura culinária e alimentar em suas obras. Lobato inclui elementos da cozinha brasileira no enredo da coleção Sítio do Picapau Amarelo e Freyre, em Casa-grande \& Senzala, respectivamente. Este último, publicado em 1933, compreende elementos dos modos de comer do país e reforça a questão da miscigenação. Quatro anos antes, em seu Manifesto Regionalista, incluiria menções sobre regiões culinárias de destaque. Já Monteiro Lobato, como editor da Companhia Editora Jangada | nr. 11, jan/jun, 2018 | ISSN 2317-4722 


\section{1 jangada}

Nacional, lançaria o livro Dona Benta: Comer Bem, em 1940 (DÓRIA, 2014).

A década de 60 é o período da publicação de História da Alimentação no Brasil, livro considerado a última pesquisa de fôlego sobre a cozinha brasileira. De autoria de Luís da Câmara Cascudo, pretendeu verificar o que compunha originariamente as influências portuguesa, indígena e africana.

\subsection{MÁRIO DE ANDRADE, MODERNISMO E CULINÁRIA BRASILEIRA}

A partir da segunda década do século XX, surge o movimento modernista em São Paulo, que impregna a literatura e as artes de nacionalismo na tentativa de reelaborar a noção de identidade cultural brasileira. Definições estas que se articulam e se materializam em diversos simbolismos e expressões que compõem a cultura material e imaterial, incluindo a cozinha.

A ideia de formação da nação brasileira por três etnias de modo equilibrado aproxima este contexto da comunicação feita pelos intelectuais do movimento modernista, nas primeiras décadas do século XX. Isto teria sido um elo significativo para a manutenção de discursos ainda vigentes sobre as qualidades da culinária brasileira e sua divisão em cozinhas regionais, nos tempos atuais.

A ideia da influência do movimento modernista no discurso vigente ainda hoje sobre a cozinha brasileira como produto de fusão racial equilibrada é apontada pelo sociólogo Carlos Alberto Dória (2014, p. 34):

\footnotetext{
Miscigenação não é um conceito simples, embora tenha se tornado banal, tanto por causa do ensino como da própria fala sobre a culinária nacional. De fato, quando Gilberto Freyre publicou Casa-grande \& Senzala (1933), pôs fim à discussão sobre a hierarquia das raças na formação da sociedade brasileira. (...) a miscigenação de brancos, negros e índios sob direção da grande propriedade rural legitimou a convicção de que éramos mestiços por definição. Ora, a ideia que Gilberto Freyre apresentou de forma convincente já circulava na cultura brasileira desde A Semana de Arte Moderna de 1922, capitaneada por Oswald de Andrade e Mário de Andrade.
}

Teriam sido criadas tradições étnicas e culturais que pudessem unir os diferentes povos 


\section{I jangada}

que aqui estavam, tornando a alimentação simbologia representativa de valores, ideias e sentimentos, reconhecida e compartilhada.

Para Leme e Basso (2014, p. 22):

a comida, tal como o território e a unidade linguística, serviria para formar esta representação da nação. A ideia era criar uma comunidade de sentido onde todos comem da mesma forma, mascarando diferenças e desigualdades - escravidão, etc - e se opondo ao estrangeiro.

Construir esta tradição marginalizou a diversidade das etnias que ocupavam o Brasil, principalmente as indígenas e africanas - oprimidas. Reafirmar um estado de espírito nacional pelos modernistas, uma identidade fruto da contribuição equilibrada entre os povos, conforme elucida Dória (2014), pode presumi-los como responsáveis pela imagem cristalizada da culinária brasileira. A cozinha, como forma de expressão da cultura, também teria sido questionada e reelaborada na criação da brasilidade, como os outros elementos da cultura brasileira (LEME; BASSO, 2014).

Segundo Oliveira (s/d, p. 14), para Mário de Andrade e os intelectuais contemporâneos a ele, "a cultura tornar-se-á, assim, elemento de transformação da realidade brasileira, bem como de cidadania”. Em seu O Ensaio Sobre a Música Brasileira, escrito em 1928, Mário propõe um programa pedagógico, ainda que pouco rigoroso quanto à teoria, comunicando ideias de identidade cultural e brasilidade na música. Nele, envolve seus leitores num "projeto de (re)descobrimento do Brasil” (Contier, 2000, p. 199-200).

Ainda que a menção anterior se refira ao universo da música brasileira, há que se destacar que há grande possibilidade de que tenha havido, via Mário, a transferência desses valores de identidade cultural e brasilidade para pensar outros elementos da cultura material e imaterial, neste caso, a cozinha. Segundo Ribeiro (2005, p. 13)

Mário de Andrade, por sua vez, parece interessado, desde o início da década de 1920, em desvendar o Brasil pelo viés da cultura popular. Por esse motivo, embora não tenha ido à Europa uma única vez, tem três destinos de viagem importantes, que são aqui abordados: Minas, Norte e Nordeste. (...) $\mathrm{Na}$ constituição da história da etnologia, muitos foram os casos em que o contato 


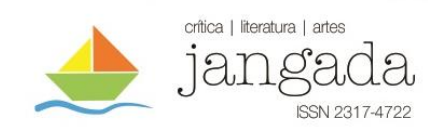

com o outro promovido pelas viagens despertou o questionamento às esferas pessoais de pertencimento

Pensar esta relação de pertencimento pela culinária pode ter sido um viés observado, em parte, em seus trabalhos como escritor. Outro fato relevante na trajetória deste intelectual modernista brasileiro é o cargo ocupado como Diretor do Departamento de Cultura da cidade de São Paulo, de 1935 a 1938. Conforme Barbato (2004, p. 51 apud OLIVEIRA, 2005, p. 15) "não há como dissociar o sentido das práticas culturais do Departamento de Cultura paulistano desse compromisso com o “ideário dos arautos da identidade nacional'”. Neste período, Mário pode mergulhar em um 'laboratório de brasilidade', reunindo estudos folclóricos e etnográficos visando "suprir as deficiências da coleta e registro das expressões da cultura popular" (VELOSO, 1982, p. 148 apud OLIVEIRA, 2005, p. 16).

A aproximação dessas evidências em suas obras com a estruturação de um discurso sobre a culinária brasileira, algo que também justifica esta pesquisa, culmina na sua proposta de criação de um restaurante de cozinha brasileira "estilizada"4, junto ao jornalista Paulo Duarte, quando trabalhou no Departamento de Cultura de São Paulo, em 1935. Embora previsto por lei, nunca teria saído do papel.

Segundo Aguiar (2016) e Dória (2016), tais informações aparecem nas cartas de Mário a Paulo Duarte, publicadas no livro Mário de Andrade por ele mesmo. Aguiar (2016) destaca o seguinte trecho:

Pois apesar desses pequenos grandes uivos, o restaurante municipal iria ser instalado dentro de poucos meses, para orgulho da cidade, alegria dos homens de gosto e para dar um pouco de verniz aos pequenos trastes de cabeceira que o ditador veio encontrar em São Paulo a fim de mobiliar o pardieiro de seu Estado Novo. Ia ser montado no Viaduto do Chá, ao lado do Teatro Municipal, onde todas as instalações seriam feitas.

\footnotetext{
${ }^{4}$ Dória aborda este tema da estilização no capítulo "Propostas para a renovação da culinária brasileira", em seu livro A Formação da Culinária Brasileira (2014, pp. 226-227). Lá, estabelece que esta estilização de restaurantes (que ocorre em uma metrópole) se relaciona a uma estratégia de renovação ao conferir-lhes uma marca pessoal (estilo), numa "diversidade de soluções adotadas: escolha de matérias-primas, técnicas utilizadas, soluções estéticas no prato e também na ambientação do restaurante. Essas diferenças configuram estilizações na maneira de apresentação da comida que deriva da culinária tradicional, mas mantendo sempre um vínculo que permite legibilidade 'brasileira' do que é proposto.
}

Jangada | nr. 11, jan/jun, 2018 | ISSN 2317-4722 150| Pág ina 


\section{1 jangada}

No capítulo "Mário de Andrade na cozinha", do livro A Cozinha Futurista, de F. T. Marinetti e Fillìa, Mancinelli esboça "analogias gastronômicas" entre o Manifesto da Cozinha Futurista e parte da obra do intelectual modernista. Destaca-se o livro Macunaíma, no qual considera "a alimentação fator fundamental para o desenrolar da obra" e um indicativo de "que [ela] pode ser uma das bases da formação do caráter nacional" para Mário. Além disso, destacase também a relevância da menção de termos culinários indígenas, africanos e europeus, identificando de certo modo o que para ele seria "a mistura das diversas culturas que integram o povo brasileiro" (MARINETTI, 2009, pp. 35-37, 41).

Segundo Mancinelli (MARINETTI, 2009, pp. 35-51), Mário de Andrade aborda a culinária como formadora da identidade nacional em outros de seus textos como "Romance do Veludo", publicado em 1928, o conto "O Peru de Natal", escrito entre 1938 e 1942, e "O Banquete", publicado entre 1943 e 1945.

No acervo de Mário de Andrade do Instituto de Estudos Brasileiros (IEB - USP) existe ainda uma coleção de cardápios de Mário de Andrade (PAULILLO, 1982), referentes ao período de 1921 e 1945. Num total de 16 menus, são citados os pratos degustados, as harmonizações propostas e alguns deles constam a assinatura de personalidades presentes nos encontros modernistas ao redor da mesa. Tais cardápios podem conter pistas relevantes para descobertas sobre um possível discurso de brasilidade à mesa promovido por ele. Há o emprego constante, por exemplo, do termo “à brasileira” às preparações culinárias servidas, terminologia bastante comum em menus na Europa (França, Itália e Portugal) e que evidencia também suas influências.

Sobre suas redes de sociabilidades, Mário teve importante contato intelectuais contemporâneos a ele que pesquisavam a cultura geral e alimentar do Brasil. Câmara Cascudo foi um deles como se pode inferir no livro que traz as cartas trocadas entre ambos ao longo de 20 anos: Câmara Cascudo e Mário de Andrade: Cartas, 1924-1944. A mesma troca de correspondências, ocorreu entre ele e Monteiro Lobato, conforme analisa Marisa Lajolo em "Mário de Andrade e Monteiro Lobato: um diálogo modernista em três tempos", edição de 2008 da Revista Teresa, da Universidade de São Paulo.

Por último, em arquivo digital indicado existente na Cinemateca do Centro Cultural São Paulo, verificou-se que Mário realizou em 1936 uma viagem com Claude Lévi-Strauss e a também antropóloga Dinah Dryfus à Festa do Divino Espírito Santo, de Mogi das Cruzes/SP. 


\section{1 jangada}

Esta é uma festa religiosa que se realiza ainda hoje e é bastante conhecida pelas comidas típicas, servidas durante todo o evento.

Assim, conclui-se que esta investigação contribui para revelar como se materializou, intencionalmente, a influência do intelectual Mário de Andrade na formação de um discurso sobre a identidade nacional pela culinária, algo que reverbera até hoje na gastronomia.

\section{CONSIDERAÇÕES FINAIS}

A cozinha, como campo de estudo interdisciplinar, dialoga com diferentes ciências, incluindo as letras. Ela está para além da materialidade culinária e pode ser compreendida tanto do ponto de vista relacional como da linguagem. Nisso reside um conjunto de operações e processos que podem expressar discursos, articulações e representações de distintos imaginários: do local, regional e nacional para diferentes grupos (algo que inclui etnia, classe, identidade e gênero), além de questões relacionadas ao tempo, à tradição e à memória (COLAÇO, s/a).

Seja em tratados e manuscritos, seja em livros de receitas, a literatura culinária aqui mencionada se relaciona, sobretudo, às elites. Indica transformações em suas práticas alimentares, equipamentos, métodos e técnicas de preparo. Inclui também gêneros alimentícios disponíveis, suas posições numa escala de valores, orientações, prescrições e exclusões alimentares.

A proclamação da República, em 1889, provoca um processo de descentralização política e administrativa no Brasil, o que propicia a tendência de reorganização do Estado em diversos aspectos. A questão da identidade nacional e regional e suas simbologias ocupa um espaço importante na transformação desta sociedade e é reforçada no período Modernista.

A reflexão sobre Mário de Andrade neste artigo dá-se em razão de suas observações e referências culinárias, sua rede de sociabilidade e culmina na identificação da existência da proposta de criação de um restaurante de cozinha brasileira "estilizada” em São Paulo, em 1935, junto com o jornalista Paulo Duarte, quando este trabalhou no Departamento de Cultura de São Paulo. Embora previsto por lei, nunca teria saído do papel.

Além disso, Mário refletiu sobre a culinária e compartilhou suas ideias com outros importantes estudiosos da cozinha brasileira, como Câmara Cascudo, Monteiro Lobato, Gilberto Freyre e até Claude Lévi-Strauss. Todos estes fatos são elementos que nos levam à 


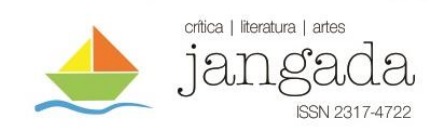

melhorar a compreensão sobre as cristalizações, menções e silenciamentos sobre a cozinha brasileira e suas cozinhas regionais.

Por fim, este artigo também visa contribuir com os estudos literários sobre Mário de Andrade sob uma perspectiva cultural pouco explorada, a culinária, e pretende também auxiliar no avanço da compreensão formal sobre a cozinha brasileira ao tentar identificar em suas obras a ideia de 'brasilidade' como suposta mistura equilibrada entre as etnias que compõem as bases da nossa nação - portugueses, indígenas e africanos - algo que reverbera ainda hoje nestes estudos e práticas e produz efeitos de estagnação. ${ }^{5}$

Assim, concluímos que se pensarmos a cozinha como espaço que integra bases culturais, históricas, sociais e materiais, ela também nos revela uma complexa teia de relações sobre nossa identidade cultural.

\section{REFERÊNCIAS BIBLIOGRÁFICAS:}

AGUIAR, Viviane. O restaurante de cozinha brasileira que nunca saiu do papel. In: Lembraria. Disponível em: < https://lembraria.com/2016/09/30/o-restaurante-de-cozinha-brasileira-quenunca-saiu-do-papel/> Acesso em mar 2017.

CAMARGOS, Marcia; SACHETTA, Vladimir. À Mesa com Monteiro Lobato. Rio de Janeiro: Senac Nacional, 2008.

COLLAÇO, Janine Helfst Leicht. Gastronomia: a trajetória de uma construção recente. Disponível em:

http://www.29rba.abant.org.br/resources/anais/1/1401745513_ARQUIVO_GastronomiaeCult ura.pdf > Acesso em nv 2017.

CONTIER, Arnaldo. Mário de Andrade e o (re)Descobrimento do Brasil. 2000. Disponível em: < revistas.pucsp.br/index.php/revph/article/download/10812/8030> Acesso em mar 2017.

\footnotetext{
${ }^{5}$ Sobre os efeitos de estagnação na compreensão da cozinha brasileira, vale retomar Dória (2014, p. 19): “... é preciso notar que a culinária de qualquer povo submetido às várias formas de dominação logo se divide em duas maneiras: a popular e a das elites. Como dois universos relativamente fechados em si, desenvolvem-se diferentes aproveitamentos das matérias-primas naturais, modos de fazer e educação do paladar, de tal sorte que a cozinha unificada que se possa chamar de "nacional" é algo que repousa mais sobre conjecturas do que sobre provas factuais. (...) De fato, só se começa a falar em cozinha brasileira, no sentido atual, após a impregnação de toda a cultura pelas ideias que nasceram da revisão do ser brasileiro, como fez o movimento modernista na primeira metade dos anos 1920, ou mesmo o movimento regionalista e o romance de 1930 no Nordeste. Na mesma época que se "descobriu" o barroco como estilo arquitetônico, armou-se o discurso sobre a culinária brasileira como fruto da amálgama de modos de comer de índios, negros e brancos. Depois, esse modelo de explicação difundiu-se pela cultura, invadindo também a indústria turística, a ponto de, hoje, as pessoas se movimentarem pelo país à cata de cacos dessa cozinha, já que, em vez de integrada, ela se apresenta como um conjunto de cozinhas regionais espalhadas pelas cinco grandes áreas sociopolíticas em que o IBGE dividiu o Brasil. (...) o que há de falacioso nessa abordagem [é] especialmente na medida em que ela deixa de lado a geografia dos ingredientes, enraizados numa enorme biodiversidade e numa história que pode ser contada de outro modo".
}

Jangada | nr. 11, jan/jun, 2018 | ISSN 2317-4722 153| P á g in a 


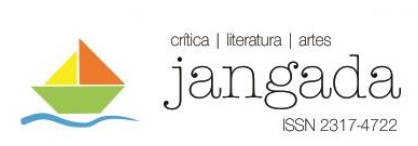

CORÇÃO, Mariana. Lembranças e esquecimentos na cozinha brasileira proposta por Câmara Cascudo. Disponível em: < www2.pucpr.br/reol/index.php/helikon?dd99=pdf\&dd1=12461 > Acesso em mar 2017.

COZINHEIRO NACIONAL ou coleção das melhores receitas das cozinhas brasileiras $e$ europeias: para preparação de sopas, molhos e carnes... / revisão Geraldo Gerson de Souza e Maria Cristina Marques. São Paulo: Atelier Editorial: Editora Senac São Paulo, 2008.

DÓRIA, Carlos Alberto. A revisitação do cozinheiro nacional. In: A cozinha nacional antes da feijoada, 2008.

. A formação da culinária brasileira: escritos sobre a cozinha inzoneira. São Paulo: Três Estrelas, 2014.

. Estrelas no céu da boca: escritos sobre culinária e gastronomia. São Paulo: Editora Senac São Paulo, 2006.

O Modernismo na "Arte Culinária” de Manuel Querino, s/d.

DÓRIA, Carlos Alberto. A cruzada de Santi Santamaria. Revista Eletrônica Trópico, 21/9/2009. Disponível em - <http://pphp.uol.com.br/tropico/html/textos/3125,1.shl> Acesso em jun 2012.

. Um "esmeril de civilização" para a gastronomia brasileira. In: E-boca Livre. 2016.

Disponível em: < http://ebocalivre.blogspot.com.br/2016/09/um-esmeril-de-civilizacaopara.html > Acesso em mar 2017.

ELIAS, Rodrigo. Feijoada: breve história de uma instituição comestível. Série Sabores do Brasil, Textos do Brasil, $\mathrm{N}^{\mathrm{o}}$ 13. 2004. Disponível em: < http://www.dc.itamaraty.gov.br/imagens-e-textos/revista-textos-do-brasil/portugues/revista13mat6.pdf > Acesso em nov. 2017.

LEME, Adriana. BASSO, Rafaela. A formação da brasilidade: a construção do discurso modernista sobre a culinária. Revista Contextos da Alimentação, Vol. $3 \mathrm{n}^{\circ} 1$ ano Dezembro de 2014. Disponível em: < http://www3.sp.senac.br/hotsites/blogs/revistacontextos/wpcontent/uploads/2014/12/35_Revista-Contextos_ed-vol-3-n-1.pdf> Acesso em dez 2016.

MARINETTI, Filippo Tommaso. A cozinha futurista (1876-1944). Tradução de Maria Lúcia Mancinelli. São Paulo: Alameda: 2009.

MARQUES, Ivan. Modernismo de pés descalços: Mário de Andrade e a Cultura Caipira. Revista IEB, n.55, 2012, mar/set. p.27-42. Disponível em: < http://www.revistas.usp.br/rieb/article/view/53895 >. Acesso em dez 2016.

NOGUEIRA, Antonio Gilberto Ramos. Inventário e patrimônio cultural no Brasil. Disponível em: 〈http://www.scielo.br/pdf/his/v26n2/a13v26n2.pdf> Acesso em mar 2017.

OLIVEIRA, Francini. Intelectuais, cultura e política na São Paulo dos anos 30: Mário de Andrade e o Departamento Municipal de Cultura. 2005. Disponível em < http://www.revistas.usp.br/plural/article/view/75669 > Acesso em Fev 2017.

PAPAVERO, Claude. Dos feijões à feijoada: a transformação de um gênero comestível pouco apreciado em mantimento básico brasileiro. 26 $6^{\mathrm{a}}$ Reunião Brasileira de Antropologia realizada entre os dias 01 e 04 de Junho de 2008 em Porto Seguro, Bahia, Brasil. Disponível em: 


\section{1 jangada}

<http://www.abant.org.br/conteudo/ANAIS/CD_Virtual_26_RBA/grupos_de_trabalho/trabal hos/GT\%2027/claude\%20papavero.pdf> Acesso em nov. 2017.

PAUliLlO, Maria Cecília R. A. Coleção de Cardápios 1921-1945, Arquivo Mário de Andrade/IEB - USP, 1982.

RIBEIRO, Monica. Arqueologia modernista: viagens e reabilitação do modernismo em Mário e Oswald de Andrade. Campinas, SP: [s. n.], 2005. Disponível em: < http://www.bibliotecadigital.unicamp.br/document/?code=vtls000379195 > Acesso em mar 2017

TREFZER, Rudolf. Clássicos da literatura culinária: os mais importantes livros da história da gastronomia. Tradução: Marcelo Rondinelli. São Paulo: Editora Senac São Paulo, 2009.

WÄTZOLD, Tim. Proclamação da cozinha brasileira como parte do processo de formação da identidade nacional no império brasileiro 1822-1889. Teses de doutorado - Universidade de Colônia, Alemanha. 348 p. Belo Horizonte: TCS Ed., 2012. Disponível em: <http://www.academia.edu/4344330/Proclama\%C3\%A7\%C3\%A3o_da_Cozinha_Brasileira_ como_parte_do_processo_de_forma\%C3\%A7\%C3\%A3o_da_identitade_nacional_no_Imperi o_Brasileiro> Acesso em dez 2016. 